\title{
Stress Corrosion in Gold Alloys
}

\author{
Jennifer M. M. Dugmore and Charles D. DesForges
}

Engelhard Industries Limited, Chessington, Surrey, England

\begin{abstract}
Although it is not often encountered, the stress corrosion cracking of low caratage gold alloys occurs in certain environments. This article reviews this phenomenon, what is known of its mechanism, and the ways in which it may be avoided or prevented.
\end{abstract}

Stress corrosion cracking is the local rupture of a metal or an alloy under the combined effects of corrosion and stress at levels well below those at which they would cause failure, were they acting independently. The phenomenon is accompanied by little evidence of corrosion products or elongation of the alloy and, as such, may seem to be spontaneous (1). Liquid metal embrittlement of pure metals has also been reported, but is generally considered to be a special case, as stress corrosion is observed in alloys rather than pure metals (2).

Stress corrosion has been the subject of much research, more usually with the intention of assessing the suitability of an alloy for a particular purpose, rather than to understand the detailed mechanism by which the phenomenon occurs. A very common incentive for such research when applied to gold-containing alloys has been the development of alternatives to the range of existing alloys which would be cheaper and yet have relatively low susceptibility to stress corrosion cracking. The main outcome of this research has, however, been an increase in the number of alloy/environment combinations known to be subject to stress corrosion cracking, rather than the development of a wide range of resistant alloys.

\section{Phenomenology of Stress Corrosion Cracking}

Stress corrosion is generally considered to occur in two stages, crack initiation and crack propagation.

Crack initiation in alloys is believed to involve the rupture of a protective surface film, combined with an electrochemical reaction (3). In the case of alloys which contain both noble and base metals, protective surface films can arise not only by reaction between base metal constituents of the alloy and its environment but also from the presence of a noble metal at the exposed surfaces of the alloy.
When considering the propagation step, problems are experienced in relating electrochemical reactions which take place under normal conditions to those in the localized crack environment. At the crack tip, new metal surface is repeatedly created by propagation and the processes occurring will be strongly dependent on variables such as the metal species exposed, oxygen and ion concentrations, crystallography and stress levels. Freshly exposed metal surfaces are believed to have high reactivity and at the tip of a crack, reactions may progress at rates that are orders of magnitude greater than those observed under equilibrium conditions.

The rate of passivation of freshly exposed metal is an important factor for both the initiation and propagation steps. When the deformation rate is high, passivation of the 'new' surface created by straining is generally too slow to prevent corrosion, and cracking will be initiated. Indeed, several investigations have established that a minimum strain rate exists, below which cracking is not observed (4). Conversely, it has also been suggested that when passivation is faster than the formation of exposed metal by cracking, the cracks cannot propagate and stress corrosion is not observed. These concepts are the basis of a mechanism proposed by Scully (5), in which the main electrochemical requirement for stress corrosion cracking to take place is a delay in the repassivation time. During this delay, a contact potential is set up along the crack and a current flows. If the strain rate at the crack tip is high enough, the rate of repassivation is too low to stop the current and ultimately the failure process.

As stress corrosion is a heterogeneous reaction, adsorption is a necessary part of the mechanism. It is often suggested that during the formation of an adsorption bond, the electron distribution in the metal lattice is altered and bond weakening results. If this weakening is significant, the strength of the metalmetal bonds may be exceeded by the tensile component of the stress which is concentrated at a crack tip and bond breaking will occur. Propagation of the crack is by a series of semi-continuous fracture steps. This is described as stress-sorption $(2,6)$.

The site of stress corrosion initiation depends on the localized distribution of the stress and on that of adsorbed species. High energy sites will be adsorbed upon preferentially. Such sites are the intersections of the surface with grain boundaries and with disloca- 
tions and atomic-scale steps emerging at the surface. The presence of faults in a material is also known to enhance the diffusion rate of alloy components $(7,8)$ which, in turn, increases the rate at which chemically reactive paths are formed within the bulk.

Swann and Pickering (9) found that cracks in copper $/ 5$ per cent gold alloy did not necessarily nucleate at accumulations of static dislocations; segregation of solute atoms was a necessary accompanying process. As adsorption takes a finite time, the defect site must remain on the metal surface for a minimum time. It has been observed experimentally that defect migration before adsorption takes place more readily in pure metals than in alloys and, in consequence, cracks are more difficult to initiate and propagate in the former. The same authors have also suggested that an observed network of tubular corrosion pits forming along preferred paths such as active slip planes could account for the cracking by ductile fracture of the walls of numerous pits. Similar proposals were made by Robertson and Bakish (10) and by Bakish (11) after a study of the copper-gold system.

\section{Discussion}

In a typical galvanic series gold appears as the most noble metal, being situated above stainless steel and titanium (8). Relatively little has been published on stress corrosion in gold alloys, a fact which may be attributed partly to the commercial significance of such information and partly to the relative immunity from such corrosion of noble metal alloys as compared with alloys of other types.

Stress corrosion of gold jewellery is only an occasional problem, as articles are not normally exposed to corrosive conditions. Specific incidents have, however, been reported, as for example in a recent American court case (12). The judge decided that evidence presented on the behaviour of rings when exposed to chlorine indicated that misuse by the customer, who regularly came into contact with chlorine and mercury, was responsible for the subsequent failure by stress corrosion. The jeweller had, at the request of the customer, attempted to reduce the size of the ring and 'shattered it into a thousand pieces'.

Stress corrosion of industrial gold alloys is also rare and has not been the subject of many research investigations. Speidel (13) reports in this issue of Gold Bulletin on the fatigue behaviour of the gold $/ 5$ per cent nickel by weight alloy, with particular attention to environmental factors and their influence on crack growth rates, which he measured quantitatively. One interesting observation made by Speidel is the minimum in fatigue crack growth rate at specific electrode potentials, but no explanation is offered for this phenomenon.

\section{Composition Effects}

The susceptibility to stress corrosion of an alloy is strongly dependent on its gold content (3,14 to 22). Experimental data and practical observations have shown that stress corrosion cracking is usually confined to alloys of caratage equal to or less than 14 . For the purpose of research on this phenomenon it is appropriate to express the gold contents of alloys in terms of atomic percentages. Thus, 9 carat alloys contain about 18 atomic per cent, and 14 carat alloys often less than 30 atomic per cent gold. In each caratage, the percentages vary according to the atomic weights and the proportions of the non-gold components present in the alloys.

Much of the published work on the stress corrosion cracking gold alloys is that of Graf and his co-workers and results were obtained using binary gold alloys. For example, Graf (15) found that the susceptibility of such alloys actually increases as the gold contents increase from 5 to between 15 or 20 atomic per cent, in which range maximum susceptibility is observed. The precise gold content at which the maximum susceptibility occurred depended on both the corrosive media and the stress applied to the alloy. When gold-copper alloys were exposed to a mixture of ammonia, water and oxygen the maximum susceptibility occurred at a gold content of about 15 atomic per cent. In the presence of hydrochloric acid the latter figure was about 20 atomic per cent and in the presence of 2 per cent ferric chloride it was about 24 atomic per cent gold. Graf also observed that as the gold content was increased above that at which the susceptibility to stress corrosion cracking was a maximum, the susceptibility dropped rapidly and the alloy appeared to become virtually immune. In other work (3), this author reported that ultimately the susceptibility dropped to a constant low value at higher gold contents, an effect he attributed to strong general surface attack. He also observed that when the stress was increased, not only did the susceptibility to stress corrosion cracking increase but its maximum was shifted towards higher gold contents.

Some examples of noble metal ionization have been reported and it has also been suggested that noble metals are transiently ionized (14). However, when examining stress corrosion in commercial gold alloys, the role of the other components of the alloy must be considered. These can be precious metals, as in some brazing alloys, but more usually the major proportion of the alloy consists of base metals, which are added both to reduce cost and to improve physical properties. Base metals common in gold alloys include nickel, copper and zinc, all of which can be ionized under normal atmospheric conditions. In general it is the base metals which chemically react during stress corrosion. 


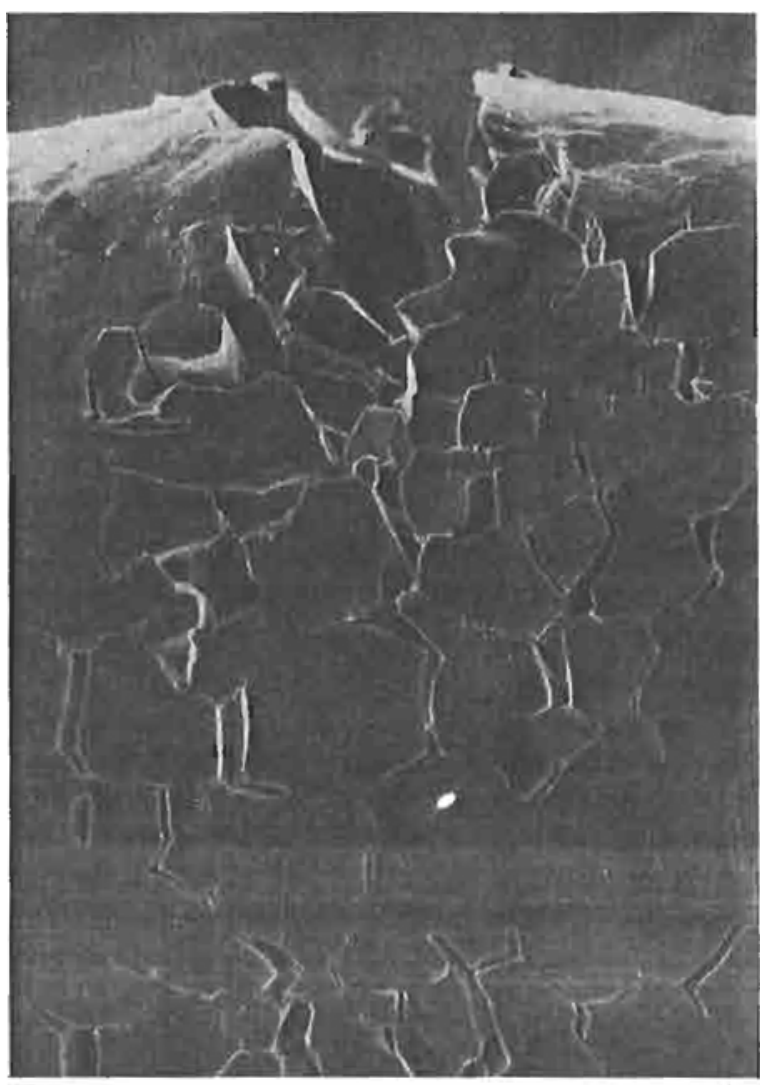

Intergranular stress corrosion in a 9 caral gold alloy after exposure under a tensile stress of $120 \mathrm{MPa}$ to $2 \mathrm{M}$ hydrochloric acid solution at room temperature $\times 380$

\section{Segregation Effects}

The distribution of the reactive components in an alloy is of equal if not greater importance than its overall composition. For example, many low carat alloys are heterogeneous and the phases have different levels of chemical reactivity, as discussed by Graf (23). Similarly if the chemically reactive components of an alloy segregate to grain boundaries and the material is stressed, it can be expected that the stress corrosion will be intergranular. Conversely, the same alloy in a different physical state may offer a different reactive path.

There are well established thermodynamic reasons why the grain boundaries and the surface of an alloy should have compositions which differ from that of the bulk. For example, segregation of one component of the alloy at the surface will occur if that component has a lower value of surface free energy. Grain boundary thickness and composition will also be governed by the need to minimize free energy. Hondros (24) suggested that grain boundary segregation may be assumed to be dependent on the orientation of the boundary, in a manner similar to anisotropic surface adsorption at a solid/gas interface. Segregation is preferentially at boundaries with higher free energies, thus ensuring that the reduction in total free energy is a maximum.
In alloy systems which display high grain boundary activity, segregation at grain boundaries can lead to changes in the matrix composition. Where the grain boundary area is large, or the grain size is small, adsorption at the grain boundaries will deplete the bulk of one component; conversely for large grains and small total grain boundary areas, the grain boundary may be saturated with segregant before the composition of the bulk is significantly affected. Such systems with high grain boundary activity exist when the solid solubility of one component is low. This effect is not restricted to alloy components and may also occur with impurity atoms. It could be partly responsible for an increase in susceptibility to intergranular stress corrosion cracking of certain alloys as their grain size is increased.

Segregation of one component to grain boundaries and surfaces has been extensively studied in recent years as a result of the availability of techniques for analysis of surfaces at atomic level. This has mostly been motivated by an interest in observed detrimental changes in mechanical properties, as in the embrittlement of steel $(25,26)$. The use of fine surface analytical techniques such as Auger electron spectroscopy (27) is generally necessary as the composition changes occur over a few atomic layers in the narrow region close to the grain boundary. A full investigation of grain boundary segregation requires a knowledge of how the segregant species are distributed across the boundary and whether and to what extent segregation depends on grain boundary configuration.

Enrichment of the gas/ or liquid/solid interface in one component has been studied mainly as a result of interest in its effect on surface tension, surface energy and catalytic activity (28). However, as this is relevant to the prediction and control of the initiation stage of stress corrosion cracking, the subject is briefly outlined here. The topic has been reviewed with emphasis on gold alloys by Bouwman (29). Other work has been published on gold-silver alloys $(30,31,32)$, but most investigations have been on alloys which do not contain gold, for example copper-nickel (33), iron-zirconium (34), silver-palladium (35) and platinum-iridium (36). In the absence of suitable analytical techniques, the general principles derived from these studies can be applied to alloy systems which have not yet been investigated.

Several theories have been put forward. The simplest model predicts that the component with the lowest sublimation energy will segregate to the surface. A second closely related model is based on the regular solution model of an alloy and relates heat of segregation to the bond strength of the elements and the number of broken bonds per atom in the surface plane (29). This theoretical model satisfactorily 
predicts the qualitative behaviour of simple alloys such as platinum $/ 5$ gold atomic per cent (37) but has not been applicable to more complex alloys. A third model for surface segregation in dilute alloys is based on strain energy due to component size mismatch. The driving force for segregation is the relief of lattice strain when atoms of a size unlike that of those of the matrix are moved from the bulk to the surface (34).

If segregation of an alloy component is indicated qualitatively, the main contributing factors in a stress corrosion failure can be identified. This method has been used in an investigation of the stress corrosion susceptibility of a 9 carat gold alloy (38). The nongold components of the alloy were silver, copper and zinc; when elements were added that were expected to have lower chemical reactivity than these metals and to segregate to the surface of the alloy, stress corrosion susceptibility dropped compared to the parent alloy. Similarly, another investigation (38) showed that one method of producing a 9 carat alloy resulted in high segregation levels of copper and zinc at the grain boundaries. The alloy produced was unusually susceptible to stress corrosion cracking. An alternative production route, however, gave a product in which silver had segregated to grain boundaries. Manufactured in this way, the alloy was stress corrosion-resistant, and under severe laboratory testing conditions its lifetime was several orders of magnitude greater. This improvement was achieved without change in the overall composition or visual appearance of the alloy.

\section{Adsorption Effects}

A major obstacle to the understanding of the surface excess concentration of certain components in alloys arises from the effects of species adsorbed from the gas or liquid phase. Adsorption can cause large changes in the composition of the outermost layer of the alloy, compared with the clean surface (29). This effect, however, can be a useful method of qualitatively predicting surface composition, if the adsorbed species is identified, and can therefore be valuable in the investigation of the initiation of a stress corrosion failure.

One system which has been examined and found to be affected by chemisorption is that of gold and nickel $(39,40)$. In this system, the components differ in atomic size and in their susceptibility to reaction with their surroundings. While the gold atoms are large and relatively inert, the nickel atoms are smaller and more reactive and have been observed to segregate to the surface to an increased extent when oxygen, hydrogen or sulphur have chemisorbed. Over most composition ranges the surface concentration of gold is consequently reduced compared with the clean alloy surface. However, prediction of effects of this

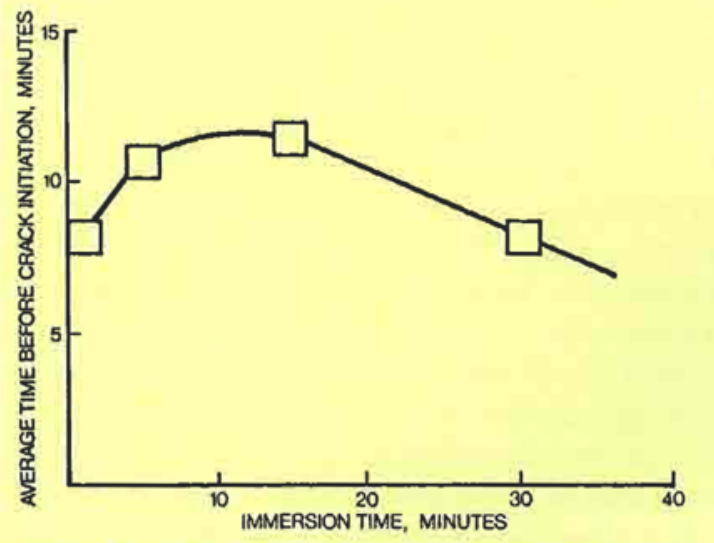

This plot of the effect of excessive pickling in 15 per cent by volume sulphuric acid on the susceptibility of a 9 carat gold alloy to stress corrosion, when subsequently exposed under a tensile stress of 220 MPa to concentrated hydrochloric acid, illustrates the necessity of carefully controlled processing conditions to avoid the phenomenon

type, especially in the case of multi-component alloys, cannot yet be made with confidence.

Predictions of surface compositions can be made with greater confidence if the most reactive component in the alloy is also that which has the lowest sublimation energy and is of a size that differs from the remaining components. One example of this is zinc, a common constituent of gold alloys. It has been observed experimentally that zinc significantly enhances the susceptibility of ternary (8) and quaternary (38) gold alloys to stress corrosion cracking.

Before an alloy is used for a new critical application, an estimate is needed of its possible susceptibility to stress corrosion cracking. As there are so many factors which contribute to this phenomenon, it is difficult to isolate any specific one in an experimental in vestigation. For this reason, tests have to be designed very carefully, particularly when a possible failure in use could have dangerous consequences or be very costly. Although the development of standard tests for stress corrosion behaviour is desirable, it is advisable for testing to be done under service conditions whenever possible. Surface composition and segregation in the bulk can affect the behaviour of an alloy and test samples must be prepared from the material in its final processing state. Particular care must be given to final annealing because both the atmosphere and cooling rate have a strong influence on the inter. facial composition of test samples and therefore upon their susceptibility to stress corrosion cracking.

\section{Prevention of Stress Corrosion Cracking}

If stress corrosion is found to be a problem in any particular application of a gold alloy it is necessary to consider its method of production, and the conditions 
under which it is stored and used. Gold alloys, particularly those of lower caratage, have been found to be susceptible to the effects of poor housekeeping (8). Examples of this include the failure of alloys which have been pickled excessively (see graph) or stored in corrosive atmospheres. Standards must be kept consistently high; the benefits in terms of reduced susceptibility have been shown to be adequate compensation for increased production costs.

However, if stress corrosion is still found in an alloy, perhaps due to the aggressive conditions of service, the easiest method of eliminating the problem is to use a more noble composition. Generally, a higher gold content is suggested $(1,8)$. An alternative is to increase the content of another noble metal constituent, and thereby decrease the content of the most reactive component. For example, larger quantities of silver may be added to gold alloys. The activity of zinc has been discussed (8), but the value of 15 per cent zinc, quoted as that below which the susceptibility to stress corrosion cracking decreases rapidly, is unlikely to hold for many alloys. The complexity of most gold alloys, particularly those intended for use in jewellery, means that composition changes of this type must be largely based on practical experience and extensive testing.

A change in composition is often not possible either on economic grounds, or as a result of changes in properties such as colour of carat gold jewellery alloys. It is then necessary to consider the effect of a change in physical state. Annealing or stress-relieving are often simple, effective and essential means of reducing the likelihood of stress corrosion. If precise monitoring of annealing conditions is possible, surface composition and segregation in the bulk of the alloy can be controlled to give an alloy of minimum susceptibility. This method is particularly attractive for jewellery manufacture where alloy compositional changes are often unacceptable. An example of stress-relieving as a method of reducing the incidence of stress corrosion cracking is given by the treatment of low carat jewellery rings. These are sometimes observed to fail, the cracking being initiated by hallmarking. A full anneal after hallmarking would result in a ring too easily damaged, so that a stress-relieving treatment can be a suitable compromise.

\section{Conclusion}

The factors controlling stress corrosion cracking have been discussed and their relevance to the phenomenon occurring in gold-containing alloys has been assessed. Although these are more resistant than most other alloys, it has to be recognized that under certain conditions gold alloys of less than 14 carat can be susceptible to stress corrosion cracking during manufacture or storage. By ensuring that good housekeeping principles are adhered to, this susceptibility can be reduced to an absolute minimum. Research is continuing on ways of further lowering this susceptibility. Progress will be based on a more complete understanding of the factors likely to cause stress corrosion cracking.

\section{References}

1 H. L. Logan, 'The Stress Corrosion of Metais', John Wiley \& Sons Inc., New York, 1966

2 M. H. Kamdar, 'Embrittlement by Liquid Metals', Pergamon Press, London, 1973

3 'The Theory of Stress Corrosion Cracking in Alloys', edited by J. C. Scully, N.A.T.O. Scientific Affairs Division, N.A.T.O. Science Committee Research Evaluation Conference, 1971

4 E. H. Dix, Trans. Am. Inst. Min. Metall. Eng, 1940, 137, $11-40$

5 P. R. Swann et al., 'Mechanisms of Environment Sensitive Cracking of Materials', Metals Society, London, 1977

6 'Physical Metallurgy of Stress Corrosion Fracture', edited by T. Rhodin, Interscience, New York, 1959

7 P. R. Swann and H. W. Pickering, Corrosion, 1963, 19, (11), 369-372

8 W. S. Rapson and T. Groenewald, 'Gold Usage', Academic Press, London, 1978

9 H. W. Pickering and P. R. Swann, Corrosion, 1963, 19, (11), 373

10 W. D. Robertson and R. Bakish, in 'Stress Corrosion Cracking and Embrittlement', edited by W. D. Robertson, John Wiley \& Sons Inc., New York, 1956, pp. 32-47

11 R. J. Bakish, Metals, 1957, 9, 494-497

12 Anon., Retail Feweller, 1977, (Nov. 10th), 34

13 M. O. Speidel, Gold Bull., 1979, 12, (4), 000-000

14 L. Graf and J. Budke, Z. Metallkd., 1955, 46, 378-385

15 L. Graf, $Z$. Metallkd., 1975, 66, 749-754

$16 \mathrm{~L}$. Graf, in 'Stress Corrosion Cracking and Embrittiement,' edited by W. D. Robertson, John Wiley \& Sons Inc., New York, 1956, pp. 48-60

17 C. H. Samans, in 'A.S.M. Metals Handbook', 1948, p. 1119

18 J. M. Hardwick and R. A. Dodd, F. Inst. Met., 1963-1964, 92, 339

19 N. Ohtani and R. A. Dodd, Corrosion, 1965, 21, 161-167

$20 \mathrm{C}$. H. Samans, in 'Proceedings of Symposium on Stress Corrosion Cracking of Metals', A.S.T.M., Philadelphia, 1945, p. 487

21 G. H. Sistare, in 'A.S.M. Metals Handbook', second edition, 1961, p. 1186

22 E. M. Wise, in 'A.S.M. Metals Handbook', second edition, 1961, p. 1186

23 L. Graf, Z. Metallkd., 1947, 38, 207-212

24 E. D. Hondros, F. Phys. (Paris), 1975, 36, Suppl. C4, 117-135

25 C. J. McMahon, A.S.T.M. Special Technical Publication, $1968,(407), 127-167$

26 E. D. Hondros and M. P. Seah, Scr. Metall., 1972, 6, 1007-1012

27 R. H. Williams, Contemp. Phys., 1978, 19, (5), 389-413

28 W. M. H. Sachtler and R. A. van Santen, Adv. Catal,, 1977, 26, 69-119

29 R. Bouwman, Gold Bull., 1978, 11, (3), 81-85

30 G. A. Somorjai and S. H. Overbury, Faraday Disc. Chem. Soc., 1975, 60, 279-290

31 G. C. Nelson, Surf. Sci., 1976, 59, 310-314

32 J. M. McDavid, 'Surface Composition and Work Function of Silver-Gold and Copper-Gold Alloys', Dissertation, University of Washington, 1975

33 G. Ertl and J. Küppers, J. Vac. Sci. Technol, 1972, 9, (2), 829-835

34 R. S. Polizzotti and J. J. Burton, F. Vac. Sci. Technol., 1977, 14, (1), 347-350

35 R. Bouwman, G. J. M. Lippits and W. M. H. Sachtler, $y$. Catal., 1972, 25, 350-361

36 F. J. Kuijers and V. Ponec, Appl. Surf. Sci., 1978, 2, 43-54

37 J. A. Schwarz, R. S. Polizzotti and J. J. Burton, f. Vac. Sci. Technol., 1977, 14, (1), 457-460

38 J. M. M. Dugmore, unpublished work

39 F. L. Williams and M. Boudart, f. Catal, 1973, 30, 438-443

40 J. J. Burton, C. R. Helms and R. S. Polizzotti, f. Chem. Phys., $1976,65,(3), 1089-1100$ 